\title{
Hydrogenation of Abies Wood and Ethanol Lignin by Hydrogen in Supercritical Ethanol in the Presence of Bifunctional Catalyst $\mathrm{Pt} / \mathrm{ZrO}_{2}$
}

\author{
Sergei V. Baryshnikov ${ }^{a}$, Angelina V. Miroshnikova ${ }^{a}$, \\ Alexandr S. Kazachenkoa, Yuriy N. Malyara,c, \\ Oxana P. Taran ${ }^{\mathrm{a}, \mathrm{c}}$, Alexandr V. Lavrenov ${ }^{\mathrm{b}}$, \\ Laurent Djakovitch ${ }^{\mathbf{d}}$ and Boris N. Kuznetsov*a,c \\ anstitute of Chemistry and Chemical Technology SB RAS \\ FRC "Krasnoyarsk Scientific Center SB RAS" \\ 50/24 Akademgorodok, Krasnoyarsk, 660036, Russia \\ ${ }^{b}$ Center of New Chemical Technologies BIC SB RAS \\ 54 Neftezavodskaya Str., Omsk, 644040, Russia \\ 'Siberian Federal University \\ 79 Svobodny, Krasnoyarsk, 660041, Russia \\ ${ }^{d}$ Institute of Research on Catalysis and the Environment of Lyon \\ 2 Albert Einstein, Lyon, F-69626, France
}

Received 21.10.2019, received in revised form 07.11.2019, accepted 23.11.2019

The effect of bifunctional catalyst $\mathrm{Pt} / \mathrm{ZrO} \mathrm{O}_{2}$ on the yield and composition of products of abies wood and ethanol lignin hydrogenation in supercritical ethanol at temperature of $250{ }^{\circ} \mathrm{C}$ was established. In the process of abies wood hydrogenation, the catalyst $\mathrm{Pt} / \mathrm{ZrO}_{2}$ increases the degree of conversion of wood from 52.0 to $65.7 \mathrm{wt. \%}$, the yield of liquid products from 31.0 to $38.1 \mathrm{wt} . \%, \%$, and also increases the content of monomeric compounds in the liquid products. In the presence of catalyst, the cellulose content in the solid product of wood catalytic hydrogenation reaches to $77.1 \mathrm{wt} . \%$, and the content of lignin and hemicelluloses decreases to $21.2 \mathrm{wt} . \%$ and $1.7 \mathrm{wt} . \%$, respectively. In the process of ethanol lignin hydrogenation the catalyst $\mathrm{Pt} / \mathrm{ZrO} \mathrm{O}_{2}$ increases the degree of lignin conversion from 86.0 to $99.4 \mathrm{wt} . \%$, the yield of liquid products from 75.0 to $90.0 \mathrm{wt} . \%$, and also reduces the yield of solid residue from 14.0 to $0.6 \mathrm{wt} . \%$ and the yield of gases from 4.7 to $3.3 \mathrm{wt} \%$. Thus, the polysaccharides of wood biomass complicate the reductive depolymerization of native lignin in comparison with the depolymerization of isolated ethanol lignin. The use of the catalyst $\mathrm{Pt} / \mathrm{ZrO} \mathrm{O}_{2}$ makes it possible to fractionate the abies wood in supercritical ethanol at $250{ }^{\circ} \mathrm{C}$ on solid product with a high content of cellulose, as well as liquid and gaseous products from lignin and hemicelluloses.

(c) Siberian Federal University. All rights reserved

* Corresponding author E-mail address: inm@icct.ru 
Keywords: abies wood, ethanol lignin, hydrogenation, supercritical ethanol, catalyst, $\mathrm{Pt} / \mathrm{ZrO}$, conversion, products yield.

Citation: Baryshnikov S.V., Miroshnikova A.V., Kazachenko A.S., Malyar Yu.N., Taran O.P., Lavrenov A.V., Djakovitch L., Kuznetsov B.N. Hydrogenation of abies wood and ethanol lignin by hydrogen in supercritical ethanol in the presence of bifunctional catalyst Pt/ZrO ${ }_{2}$, J. Sib. Fed. Univ. Chem., 2019, 12(4), 550-561. DOI: 10.17516/1998-2836-0150.

\title{
Гидрирование древесины
}

\author{
и Этаноллигнина пихты водородом \\ в среде сверхкритического этанола в присутствии \\ бифункционального катализатора $\mathrm{Pt} / \mathrm{ZrO}_{2}$
}

\author{
С.В. Барышников, А.В. Мирошникова ${ }^{a}$, \\ А.С. Казаченко ${ }^{\text {a }}$ Ю.Н. Маляр, ${ }^{\text {a, }}$ О.П. Таран ${ }^{\text {a, }}$, \\ А.В. Лавренов ${ }^{\sigma}$, Л. Дьякович \\ ${ }^{a}$ Институт химии и химической технологии СО РАН \\ ФИЦ «Красноярский научный иентр СО РАН» \\ Россия, 660036, Красноярск, Академгородок, 50/24

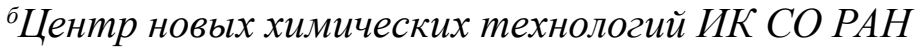 \\ Россия, 644040, Омск, ул. Нефтезаводская, 54 \\ ${ }^{6}$ Сибирский федеральный университет \\ Россия, 660041, Красноярск, пр. Свободный, 79 \\ 'Институт исследований катализа и окружающей среды \\ Франция, 69626, Лион
}

Установлено влияние бифункиионального катализатора $\mathrm{Pt} / \mathrm{ZrO} \mathrm{O}_{2}$ на выход и состав продуктов гидрирования древесины пихты и этаноллигнина пихты в среде сверхкритического этанола при температуре $250{ }^{\circ} \mathrm{C}$. В прочессе гидрирования древесины пихты катализатор $\mathrm{Pt} / \mathrm{ZrO} \mathrm{O}_{2}$ повымает степень превращения древесины с 52,0 до 65,7 мас.\%, выход жидких продуктов с 31,0 до 38,1 мас.\%, а также увеличивает содержание мономерных соединений в жидких продуктах. В присутствии катализатора содержание иеллюлозы в твердом продукте проиесса каталитического гидрирования древесины достигает 77,1 мас.\%, а содержание лигнина и гемицеллюлоз уменьшается до 21,2 и 1,7 мас.\% соответственно. При гидрировании

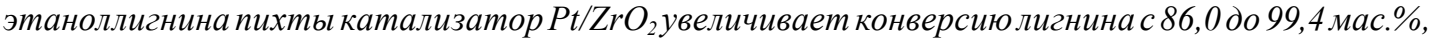
выход жидких продуктов - с 75,0 до 90,0 мас.\%, а также уменьшает выход твердого остатка с 14,0 до 0,6 мас.\% и выход газов с 4,7 до 3,3 мас.\%. Таким образом, полисахариды древесной биомассы затрудняют восстановительную деполимеризацию нативного лигнина по сравнению с деполимеризачией выделенного этаноллигнина. Применение катализатора $\mathrm{Pt} / \mathrm{ZrO} \mathrm{O}_{2}$ позволяет осуществить восстановительное фракционирование древесины пихты в сверхкритическом 
этаноле при $250{ }^{\circ} \mathrm{C}$ с получением твердого продукта с высоким содержанием целлюлозы, а также жидких и газообразных продуктов из лигнина и гемицеллюлоз.

Ключевые слова: древесина пихты, этаноллигнин, гидрирование, сверхкритический этанол, катализатор, $\mathrm{Pt} / \mathrm{ZrO}_{2}$, конверсия, выход продуктов.

\section{Введение}

Древесная биомасса - широко распространенный возобновляемый источник органического сырья. Перспективные технологии комплексной переработки древесины основаны на предварительном фракционировании ее биомассы на основные структурные компоненты: целлюлозу, лигнин и гемицеллюлозы [1]. Одним из эффективных методов выделения лигнина является экстракция лигноцеллюлозных материалов легкокипящими органическими растворителями либо их смесями с водой (метод органосольвентной варки) [2, 3]. Получаемые органосольвентные лигнины не содержат серу и имеют более высокую реакционную способность по сравнению с традиционными техническими лигнинами $[4,5]$.

Превращение органосольвентных лигнинов в низкомолекулярные соединения может быть эффективно осуществлено методом термического растворения в среде низших алифатических спиртов, находящихся в сверхкритическом состоянии. Подходящим для этого процесса растворителем признан этанол $[6,7]$. Он дешев, экологичен и может быть получен в достаточном количестве из любого лигноцеллюлозного сырья с использованием существующих промышленных технологий. В процессе терморастворения спирты экстрагируют продукты термической фрагментации лигнина, одновременно алкилируя и восстанавливая интермедиаты, снижая вклад вторичных реакций их конденсации $[8,9]$.

Каталитическое гидрирование лигнинов водородом в присутствии твердых катализаторов $\mathrm{Ru} / \mathrm{C}$ [3, 10], $\mathrm{Pt} / \mathrm{C}$ [11, 12], $\mathrm{Rh} / \mathrm{C}$ [13], $\mathrm{ZnPd} / \mathrm{C}$ [14], Ni/C [15] сопровождается ростом степени их деполимеризации и увеличением выхода мономерных и димерных фенольных продуктов по сравнению с некаталитическим терморастворением лигнинов в алифатических спиртах. В процессах восстановительного каталитического фракционирования лигноцеллюлозного сырья в алифатических спиртах выделение лигнина одновременно сопровождается его деполимеризацией и реакциями стабилизации с образованием жидких низкомолекулярных продуктов и твердого карбогидратного остатка $[13,16,17]$. Наиболее высокой эффективностью в процессах восстановительной деполимеризации лигнина отличаются бифункциональные катализаторы, содержащие кислотные и металлические активные центры [18].

В данной работе проведено исследование процессов гидрирования древесины и этаноллигнина пихты в присутствии бифункционального катализатора $\mathrm{Pt} / \mathrm{ZrO}{ }_{2}$ с целью установления влияния катализатора, а также углеводных компонентов на деполимеризацию лигнина, выходы жидких, твердых и газообразных продуктов.

\section{Экспериментальная часть}

\section{Подготовка образцов древесины пихты}

В работе использовали древесину пихты, содержащую (\% в расчете на массу абсолютно сухой древесины): 45,7 - целлюлозы; 25,3 - лигнина; 17,7 - гемицеллюлоз; 6,2 - экстрактивных 
веществ; 0,5 - золы. Древесину измельчали до размеров частиц менее 1 мм на вибростенде BP-2 и последовательно обессмоливали петролейным эфиром и ацетоном (в соответствии со стандартным методом ANSI/ASTM D 1105), затем высушивали при $80^{\circ} \mathrm{C}$ до влажности менее 1 мас.\%.

Извлечение этаноллигнина из обессмоленной древесины осуществляли экстракцией смесью этанол-вода при температуре $185^{\circ} \mathrm{C}$ и последующим осаждением холодной водой по методике [19].

\section{Методика получения катализатора}

Катализатор $\mathrm{Pt} / \mathrm{ZrO}_{2}$ был приготовлен по методике [20]. Гидроксид циркония получали медленным осаждением из водного раствора $1 \mathrm{M} \mathrm{ZrO}\left(\mathrm{NO}_{3}\right)_{2}$ с молярным избытком $\mathrm{NH}_{4} \mathrm{OH}$. Осадок сушили при $120{ }^{\circ} \mathrm{C}$ и обрабатывали $2 \mathrm{M}$ раствором серной кислоты. Полученный сульфатированный материал сушили при $120{ }^{\circ} \mathrm{C}$ и прокаливали при $650{ }^{\circ} \mathrm{C}$ в потоке воздуха. Для приготовления бифункционального катализатора носитель пропитывали раствором $\mathrm{H}_{2} \mathrm{PtCl}_{6}$ из расчета достижения 1 мас.\% платины в образце катализатора. После нанесения платины образец сушили при $120{ }^{\circ} \mathrm{C}$ и прокаливали при $450{ }^{\circ} \mathrm{C}$ в токе воздуха. Катализатор $\mathrm{Pt} / \mathrm{ZrO}_{2}$ содержит $\mathrm{SO}^{-2}$ 5,9 мас.\%, остальное $\mathrm{ZrO}_{2}$, его поверхность составляет $110 \mathrm{M}^{2} / \Gamma$ и объем пор $0,09 \mathrm{~cm}^{3} / \Gamma$.

\section{Гидрирование древесины и этаноллигнина пихты}

Процесс гидрирования осуществляли в автоклаве ChemRe SYStem R-201 (Корея) объемом 300 мл. В реактор загружали 50 мл этанола, 5,0 г субстрата и 0,5 г катализатора. Затем автоклав герметично закрывали и продували аргоном для удаления воздуха. Подавали водород, начальное давление которого составляло 4 МПа. Реакцию проводили при постоянном перемешивании со скоростью 800 об/мин при температуре $250{ }^{\circ} \mathrm{C}$ в течение 3 ч. Скорость подъема температуры составляла $10{ }^{\circ} \mathrm{C} /$ мин, время выхода на требуемую температуру 20-25 мин. Рабочее давление в реакторе равнялось 9.0 МПа. После охлаждения реакционной смеси до комнатной температуры газообразные продукты собирали в газометр, измеряли их объем и устанавливали состав методом газовой хроматографии. Затем продукты реакции количественно выгружали из автоклава вымыванием этанолом, полученную смесь жидких и твердых продуктов разделяли фильтрованием.

Твердый продукт промывали этанолом до тех пор, пока растворитель не становился бесцветным. Из жидкого продукта удаляли растворитель на роторном испарителе, продукт доводили до постоянной массы сушкой под вакуумом (1 мм рт. ст.) при комнатной температуре. После экстракции твердый продукт высушивали до постоянной массы при $80^{\circ} \mathrm{C}$, затем экстрагировали его водой в Сокслете в течение 2 ч. Твердый продукт сушили при температуре $80{ }^{\circ} \mathrm{C}$ до постоянного веса. Выход жидких продуктов $\left(\alpha_{1}\right)$, выход твердого продукта $\left(\alpha_{2}\right)$, суммарный выход газообразных продуктов $\left(\alpha_{3}\right)$, степень превращения древесины $\left(\chi_{\pi}\right)$ и степень превращения лигнина $\left(\chi_{\mathrm{I}}\right)$ определяли по формулам 1-5:

$$
\alpha_{1}=\frac{m_{\text {ж }}(г)}{m_{\text {исх }}(г)} \times 100 \%
$$




$$
\begin{aligned}
& \alpha_{2}=\frac{m_{\text {тв } *}(г)-m_{\text {кт }}(г)}{m_{\text {исх }}(г)} \times 100 \%, \\
& \alpha_{3}=\frac{m_{г}(г)}{m_{\text {исх }}(г)} \times 100 \%, \\
& \chi_{\text {д }}=\frac{m_{\text {исх }}(г)+m_{\text {кт }}(г)-m_{\text {тв* }}(г)}{m_{\text {исх }}(г)} \times 100 \%, \\
& \chi_{л}=\frac{m_{л}-m_{Л}^{*}}{m_{л}} \times 100 \%
\end{aligned}
$$

где $m_{\text {ж }}$ масса жидких продуктов (г); $m_{u c x}-$ масса исходного образца (г); $m_{m 6^{*}}-$ масса твердого остатка после экстракции водой (г); $m_{\kappa m}$ - масса катализатора (г); $m_{2}$ - масса газообразных продуктов (г); $m_{n}-$ масса лигнина (г); $m_{л}{ }^{*}$-масса лигнина в твердом остатке.

\section{Исследование продуктов гидрирования этаноллигнина}

\section{и древесины пихты}

Состав газообразных продуктов термопревращения этаноллигнина и древесины пихты в сверхкритическом этаноле определяли методом ГХ на хроматографе «Кристалл $2000 \mathrm{M»} \mathrm{(«Хро-}$ матек», Россия) с детектором по теплопроводности. Газ-носитель - гелий (расход 15 мл/мин). Температура детектора $170{ }^{\circ} \mathrm{C}$. Для анализа $\mathrm{CO}$ и $\mathrm{CH}_{4}$ использовали колонку с цеолитом $\mathrm{NaX}$ $\left(3 \mathrm{M} \times 2\right.$ мм) в изотермическом режиме при температуре $60{ }^{\circ} \mathrm{C}$. Анализ $\mathrm{CO}_{2}$ и углеводородных газов проводили на колонке с Porapak Q в режиме: 1 мин $-60{ }^{\circ} \mathrm{C}$ и далее повышение температуры до $180{ }^{\circ} \mathrm{C}$ со скоростью $10^{\circ} \mathrm{C} /$ мин.

Твердый продукт термопревращения древесины пихты анализировали на содержание гемицеллюлоз, целлюлозы и лигнина. Содержание остаточного лигнина в твердом продукте устанавливали с использованием гидролиза $72 \%$-ной серной кислотой по методу Комарова [21], гемицеллюлоз - гидролизом 2\%-ной соляной кислоты по методу Макэна и Шоорли [22].

Молекулярно-массовое распределение образцов жидких продуктов определяли с помощью метода гельпроникающей хроматографии в хроматографе Agilent 1260 Infinity II MultiDetector GPC/SEC System с тройным детектированием: рефрактометром (RI), вискозиметром (VS) и светорассеянием (LS). Разделение проводили на колонке PLgel Mixed-E с помощью в качестве подвижной фазы тетрагидрофурана, стабилизированного 250 ррт бутилгидрокситолуола. Калибровку колонки осуществляли с использованием полидисперсных стандартов полистирола (Agilent, США). Скорость подачи элюента 1 мл/мин, объем вводимой пробы 100 мкл. Перед анализом образцы растворяли в ТГФ (1 мГ/мл) и фильтровали через 0.45 мкм мембранный ПТФЭ-фильтр (Millipore). Сбор и обработку данных выполняли с применением программного обеспечения Agilent GPC/SEC MDS.

Элементный состав древесины, жидких и твердых продуктов ее превращения определяли с использованием анализатора HCNS-O EAFLAS HTM 1112 («Thermo Quest»). 


\section{Результаты и обсуждение}

\section{Каталитическое гидрирование древесины пихты}

\section{в сверхкритическом этаноле}

Лигноцеллюлозная биомасса имеет сложную структуру, сформированную из трех основных биополимеров: целлюлозы, лигнина и гемицеллюлоз [1]. Влияние полисахаридных компонентов на термокаталитическую деполимеризацию лигнина исследовано мало. Нами сопоставлены особенности восстановительной деполимеризации нативного и выделенного этаноллигнина из древесины пихты в присутствии бифункционального катализатора $\mathrm{Pt} / \mathrm{ZrO}{ }_{2}$.

В процессе некаталитического гидрирования древесины пихты в сверхкритическом этаноле при температуре $250{ }^{\circ} \mathrm{C}$ ее конверсия составила 52 мас.\%, выход жидких продуктов 31 мас.\%, твердого продукта - 48 мас.\%, газов - 4,8 мас.\%.

В присутствии катализатора $\mathrm{Pt} / \mathrm{ZrO}_{2}$ конверсия древесины возросла до 65,7 мас.\%, выход жидких продуктов - до 38,1 мас.\%, газов - до 6,8 мас.\%, а выход твердого продукта уменьшился до 34,3 мас.\% (табл. 1). В процессе каталитического гидрирования древесины пихты наблюдалась значительно более высокая концентрация паров воды в газовой фазе по сравнению с некаталитическим процессом, что, вероятно, обусловлено протеканием реакций дегидратации углеводов и их производных на кислотных центрах катализатора.

Катализатор $\mathrm{Pt} / \mathrm{ZrO}_{2}$ повышает выход газов и значительно изменяет соотношение $\mathrm{CO}, \mathrm{CO}_{2}$ и $\mathrm{CH}_{4}$ (рис. 1). Резкое увеличение выхода монооксида и диоксида углерода, очевидно, свиде-

Таблица 1. Конверсия и выход продуктов гидрирования древесины пихты в сверхкритическом этаноле при $250{ }^{\circ} \mathrm{C}$

Table 1. Conversion and yield of products of abies wood hydrogenation in supercritical ethanol at $250{ }^{\circ} \mathrm{C}$

\begin{tabular}{|c|c|c|c|c|}
\hline Катализатор & Конверсия, мас.\% & $\begin{array}{c}\text { Выход жидких } \\
\text { продуктов, мас.\% }\end{array}$ & $\begin{array}{c}\text { Выход твердых } \\
\text { продуктов, мас.\% }\end{array}$ & Выход газов, мас.\% \\
\hline Отсутствует & 52,0 & 31,0 & 48,0 & 4,8 \\
\hline $\mathrm{Pt} / \mathrm{ZrO}_{2}$ & 65,7 & 38,1 & 34,3 & 6,8 \\
\hline
\end{tabular}

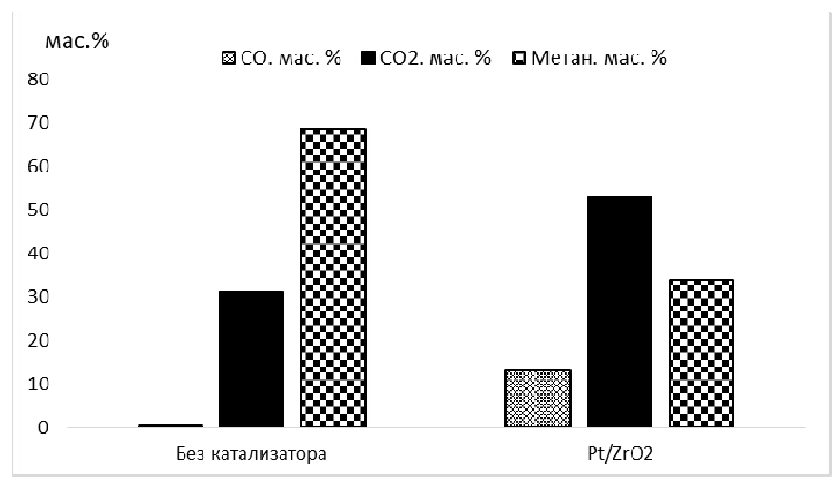

Рис. 1. Состав газообразных продуктов гидрирования древесины пихты в сверхкритическом этаноле при $250{ }^{\circ} \mathrm{C}$

Fig. 1. Composition of the gaseous products of abies wood hydrogenation in supercritical ethanol at $250{ }^{\circ} \mathrm{C}$ 
тельствует об интенсификации реакции декарбонилирования и декарбоксилирования в присутствии бифункционального катализатора $\mathrm{Pt} / \mathrm{ZrO}_{2}$.

По данным химического анализа, твердый остаток процесса некаталитического гидрирования древесины пихты содержит 66,5 мас.\% целлюлозы и 30,5 мас.\% лигнина. В присутствии катализатора $\mathrm{Pt} / \mathrm{ZrO}_{2}$ содержание целлюлозы в твердом продукте возрасло до 77,1 мас.\%, а лигнина снизилось до 21,2 мас.\% (рис. 2).

Твердые продукты процесса гидрирования древесины пихты при $250{ }^{\circ} \mathrm{C}$ содержат лишь небольшие количества гемицеллюлоз (1,7-3,0 мас.\%). В присутствии катализатора заметно увеличивается конверсия лигнина (рис. $2 B$ ).

Как следует из данных элементного анализа, при гидрировании древисины пихты в присутствии катализатора $\mathrm{Pt} / \mathrm{ZrO}_{2}$ интенсифицируются реакции деоксигинации, приводящие к снижению содержания кислорода в жидких продуктах гидрирования (табл. 2).

Основной вклад в количество кислорода в древесине вносит целлюлоза, содержание которой в твердых продуктах некаталитического и каталитического гидрирования при $250{ }^{\circ} \mathrm{C}$ составило 66.5 и 77.1 мас.\% соответственно (рис. 2). Содержание кислорода в жид-
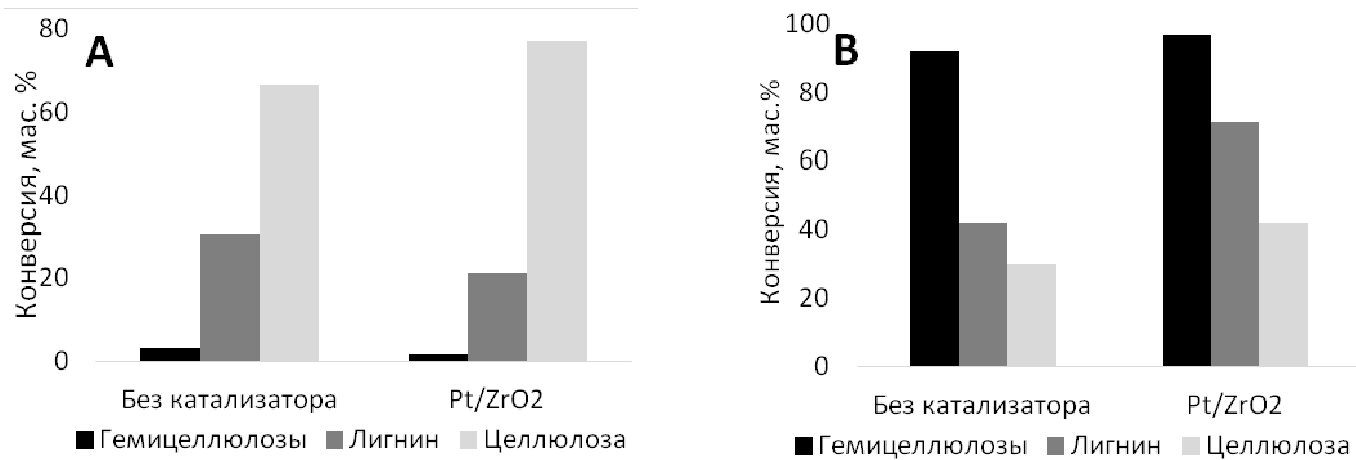

Рис. 2. Состав твердых продуктов гидрирования древесины пихты (А) и конверсия (В) структурных компонентов древесины пихты в процессе гидрирования в сверхкритическом этаноле при $250{ }^{\circ} \mathrm{C}$

Fig. 2. Composition of solid products (A) and the conversion (B) of structural components of abies wood in the hydrogenation process in supercritical ethanol at $250{ }^{\circ} \mathrm{C}$

Таблица 2. Данные элементного анализа древесины пихты, твердых и жидких продуктов гидрирования древесины в сверхкритическом этаноле при $250{ }^{\circ} \mathrm{C}$

Table 2. Data of elemental analysis of the abies wood, solid and liquid products of wood hydrogenation in supercritical ethanol at $250{ }^{\circ} \mathrm{C}$

\begin{tabular}{|l|c|c|c|}
\hline \multicolumn{1}{|c|}{ Образец } & $\mathrm{C}$, мас.\% & $\mathrm{H}$, мас.\% & О, мас.\% \\
\hline Исходная древесина пихты & 48,51 & 5,73 & 45,76 \\
\hline Целлюлоза (расчет) & 44,40 & 6,20 & 49,40 \\
\hline Жидкие продукты некаталитического гидрирования & 62,00 & 7,31 & 30,69 \\
\hline Жидкие продукты гидрирования в присутствии катализатора $\mathrm{Pt} / \mathrm{ZrO}_{2}$ & 64,02 & 7,99 & 27,99 \\
\hline Твердый продукт некаталитического гидрирования & 53,64 & 5,47 & 40,89 \\
\hline Твердый продукт гидрирования в присутствии катализатора $\mathrm{Pt} / \mathrm{ZrO}_{2}$ & 52,46 & 5,67 & 41,87 \\
\hline
\end{tabular}




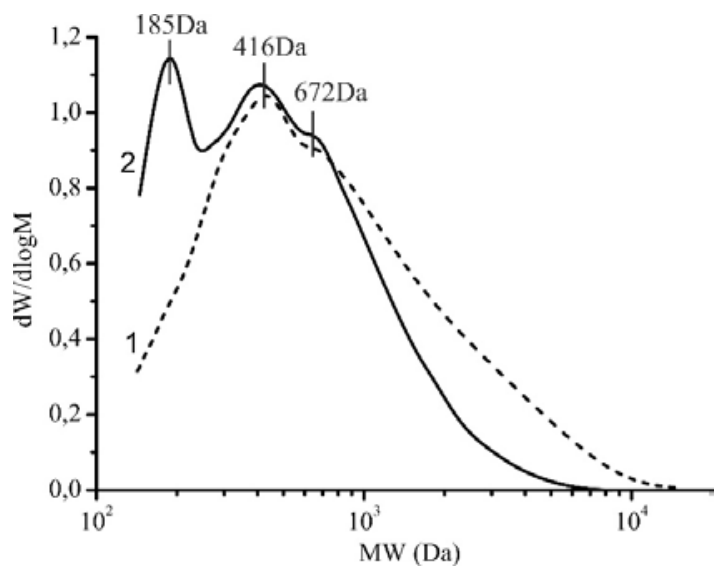

Рис. 3. Кривые молекулярно-массового распределения жидких продуктов, полученных при гидрировании древесины пихты: 1 - без катализатора; 2 - $\mathrm{Pt} / \mathrm{ZrO}_{2}$

Fig. 3. Molecular mass distribution curves of liquid products obtained by hydrogenation of abies wood: 1 without catalyst; $2-\mathrm{Pt} / \mathrm{ZrO}_{2}$

ких продуктах, образующихся преимущественно в результате деполимеризации гемицеллюлоз и лигнина, ниже, чем в твердых лигноцеллюлозных продуктах. В присутствии катализатора $\mathrm{Pt} / \mathrm{ZrO}_{2}$ в жидких продуктах снижается содержание кислорода и увеличивается содержание водорода по сравнению с жидкими продуктами некаталитического гидрирования древесины.

Методом гельпроникающей хроматографии установлено, что в отсутствие катализатора происходит деполимеризация древесных полимеров с образованием соединений со среднемассовой молекулярной массой $(\mathrm{Mw}) 1211$ г/моль и полидиперсностью 2.285. В присутствии катализатора $\mathrm{Pt} / \mathrm{ZrO}_{2}$ уменьшается молекулярная масса жидких продуктов $\left(\mathrm{M}_{\mathrm{w}}\right)$ до 793 г/моль и полидисперсность до 1.756.

По сравнению с некаталитическим процессом в присутствии катализатора происходит более глубокий процесс деполимеризации, что выражается в сильном смещении кривой молекулярно-массового распределения в сторону более низких молекулярных масс (рис. 3). Для жидких продуктов некаталитического и каталитического гидрирования характерны общие пики с МM 416 и $~ 672$ г/моль, вероятно соответствующие олигомерным соединениям. Однако отличительной особенностью кривой ММР продуктов каталитического гидрирования древесины пихты является наличие пика с ММ 185 г/моль, свидетельствующего о присутствии значимого количества мономерных соединений.

\section{Каталитическое гидрирование этаноллигнина пихты}

в сверхкритическом этаноле

В процессе некаталитического гидрирования этаноллигнина в сверхкритическом этаноле при температуре $250{ }^{\circ} \mathrm{C}$ его конверсия составила 86 мас.\% от исходного лигнина, выход жидких продуктов - 75 мас.\%, твердого продукта - 14 мас.\% (табл. 3). В присутствии катализатоpa $\mathrm{Pt} / \mathrm{ZrO}_{2}$ конверсия этаноллигнина возросла до 99,4 мас.\%, выход жидких продуктов - до 90 мас.\%, а выход твердого остатка уменьшился до 0,6 мас.\%. Известно [23], что металлические 
Таблица 3. Конверсия и выход продуктов гидрирования этаноллигнина пихты в сверхкритическом этаноле при $250{ }^{\circ} \mathrm{C}$

Table 3. Conversion and yield of products of abies ethanol lignin hydrogenation in supercritical ethanol at $250{ }^{\circ} \mathrm{C}$

\begin{tabular}{|c|c|c|c|c|}
\hline Катализатор & Конверсия, мас.\% & $\begin{array}{c}\text { Выход жидких } \\
\text { продуктов, } \\
\text { мас.\% }\end{array}$ & $\begin{array}{c}\text { Выход твердых } \\
\text { продуктов, } \\
\text { мас.\% }\end{array}$ & Выход газов, мас.\% \\
\hline Отсутствует & 86,0 & 75,0 & 14,0 & 4,7 \\
\hline $\mathrm{Pt} / \mathrm{ZrO}_{2}$ & 99,4 & 90,0 & 0,6 & 3,3 \\
\hline
\end{tabular}

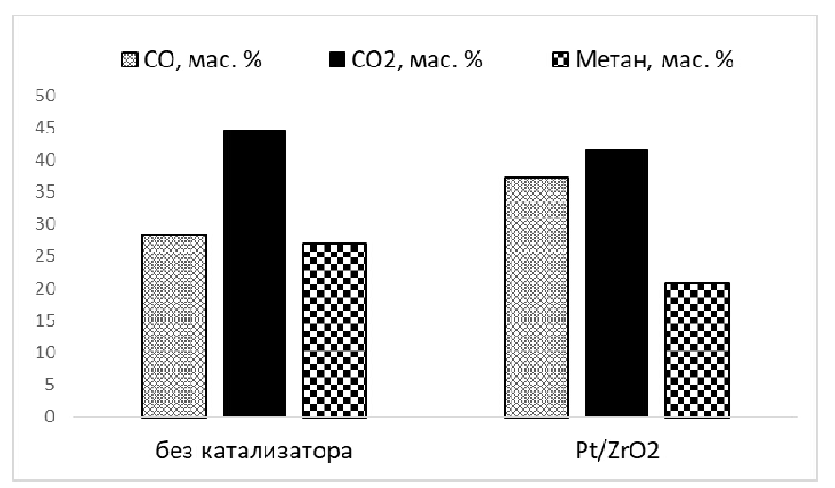

Рис. 4. Состав газообразных продуктов процесса каталитического гидрирования этаноллигнина пихты в сверхкритическом этаноле при $250{ }^{\circ} \mathrm{C}$

Fig. 4. The composition of the gaseous products of the process of catalytic hydrogenation of abies ethanol lignin in supercritical ethanol at $250^{\circ} \mathrm{C}$

центры бифункциональных катализаторов в атмосфере водорода способствуют стабилизации низкомолекулярных продуктов. Это приводит к подавлению реакций реполимеризации активных интермедиатов и, как следствие, к увеличению выхода низкомолекулярных продуктов и резкому падению выхода твердого остатка.

Основные компоненты газообразных продуктов - оксиды углерода и метан, которые образуются в результате протекания реакций декарбонилирования, декарбоксилирования и крекинга [24]. В присутствии катализатора их выход примерно в полтора раза выше по сравнению с некаталитическим процессом, однако катализатор слабо влияет на соотношение $\mathrm{CO}, \mathrm{CO}_{2}$ и $\mathrm{CH}_{4}$ (рис. 4).

Результаты выполненного исследования показали, что выделенный из древесины пихты этаноллигнин легче подвергается восстановительной деполимеризации в среде сверхкритического этанола, чем нативный лигнин пихты. Находящиеся в составе древесины углеводные компоненты химически связаны с нативным лигнином, что препятствует его растворению в среде этанола. В связи с этим существенно снижается конверсия нативного лигнина в жидкие продукты по сравнению с выделенным этаноллигнином. 


\section{Заключение}

Сопоставлены особенности восстановительной деполимеризации в среде сверхкритического этанола при $250^{\circ} \mathrm{C}$ нативного и выделенного из древесины пихты этаноллигнина в присутствии бифункционального катализатора $\mathrm{Pt} / \mathrm{ZrO}_{2}$.

В процессе некаталитического гидрирования древесины пихты её конверсия составила 52 мас.\%, выход жидких продуктов - 31 мас.\%, твердого продукта - 48 мас.\%, газов - 4,8 мас.\%. В присутствии катализатора $\mathrm{Pt} / \mathrm{ZrO}_{2}$ конверсия древесины выросла до 65,7 мас.\%, выход жидких продуктов - до 38,2 мас.\%, газов - до 6,8 мас.\%, а выход твердого продукта уменьшился до 34,3 мас.\%.

Твердый продукт каталитического гидрирования древесины содержит 77,1 мас.\% целлюлозы, 21,2 мас.\% лигнина и 1,7 мас.\% гемицеллюлоз.

Под действием катализатора $\mathrm{Pt} / \mathrm{ZrO}_{2}$ снижается содержание кислорода и увеличивается содержание водорода в жидких продуктах по сравнению с жидкими продуктами некаталитического гидрирования древесины.

В процессе некаталитического гидрирования конверсия этаноллигнина составляет 85 мас.\%, выход жидких продуктов - 75 мас.\%, твердого продукта - 14 мас.\%. В присутствии катализатора $\mathrm{Pt} / \mathrm{ZrO}_{2}$ степень превращения этаноллигнина возрастает до 99,4 мас.\%, выход жидких продуктов - до 90 мас.\%, а выход твердых продуктов снижается до 0,6 мас.\%.

Таким образом, карбогидратные компоненты древесной биомассы затрудняют восстановительную деполимеризацию нативного лигнина по сравнению с деполимеризацией выделенного этаноллигнина.

Методом гельпроникающей хроматографии установлено, что в процессе гидрирования древесины пихты в среде сверхкритического этанола происходит образование жидких продуктов со среднемассовой молекулярной массой $(\mathrm{Mw}) 1211$ г/моль. В присутствии катализатора $\mathrm{Pt} / \mathrm{ZrO}_{2}$ уменьшается среднемассовая молекулярная масса жидких продуктов (Mw) до 793 г/моль и полидисперсность с 2.285 до 1.756.

В результате выполненного исследования установлено, что применение катализатора $\mathrm{Pt} / \mathrm{ZrO}_{2}$ в процессе гидрирования древесины пихты в сверхкритическом этаноле при $250{ }^{\circ} \mathrm{C}$ позволяет осуществить восстановительное фракционирование древесной биомассы на лигноцеллюлозный продукт с высоким содержанием целлюлозы, жидкие и газообразные продукты из лигнина и гемицеллюлоз.

\section{Благодарности}

Исследования выполнены при частичной финансовой поддержке РФФИ (проект 18-5316001 НЦНИЛ_а) в рамках Международного научного объединения «Биомасса» между Францией и Россией и базового проекта № 0356-2016-0505 (V.46.4.2).

\section{Список литературы}

1. SchutyserW., Renders T., Van den Bosch S., Koelewijn S.F., Beckham G.T., Sels B.F. Chemicals from lignin: an interplay of lignocellulose fractionation, depolymerisation, and upgrading. Chemical Society Reviews 2018. Vol. 47(3), P. 852-908.

$$
-559-
$$


2. Kuznetsov B.N., Chesnokov N.V., Yatsenkova O.V., Sharypov V.I., Garyntseva N.V., Ivanchenko N.M., V.A. Y. Green catalytic valorization of hardwood biomass into valuable chemicals with the use of solid catalysts. Wood Sci. Technol. 2017. Vol. 51, P. 1189-1208.

3. Van den Bosch S., Schutyser W., Vanholme R., Driessen T., Koelewijn S. F., Renders T., De Meester B., Huijgen W.J.J., Dehaen W., Courtin C.M., Lagrain B., Boerjan W., Sels B.F. Reductive lignocellulose fractionation into soluble lignin-derived phenolic monomers and dimers and processable carbohydrate pulps. Energy \& Environmental Science 2015. Vol. 8(6), P. 1748-1763.

4. Zhang K., Pei Z.J., Wang D. Organic solvent pretreatment of lignocellulosic biomass for biofuels and biochemicals: A review. Bioresource technology. 2015. Vol. 199. P. 21-33.

5. Huijgen W.J.J., Smit A.T., de Wild P.J., den Uil H. Fractionation of wheat straw by prehydrolysis, organosolv delignification and enzymatic hydrolysis for production of sugars and lignin. Bioresource Technology 2012. Vol. 114, P. 389-398.

6. Løhre C., Barth T., Kleinert M. The effect of solvent and input material pretreatment on product yield and composition of bio-oils from lignin solvolysis. Journal of Analytical and Applied Pyrolysis 2016. Vol. 119, P. 208-216.

7. Huang X., Korányi T.I., Boot M.D., Hensen E.J.M. Catalytic Depolymerization of Lignin in Supercritical Ethanol. ChemSusChem. 2014. Vol. 7(8), P. 2051-2051.

8. Kuznetsov B.N., Sharypov V.I., Chesnokov N.V., Beregovtsova N.G., Baryshnikov S.V., Lavrenov A.V., Vosmerikov A.V., V.E. A. Lignin Conversion in Supercritical Ethanol in the Presence of Solid Acid Catalysts. Kinetika I Kataliz 2015. Vol. 56(4), P. 436-444.

9. Macala G.S., Matson T.D., Johnson C.L., Lewis R.S., Iretskii A.V., Ford P.C. Hydrogen Transfer from Supercritical Methanol over a Solid Base Catalyst: A Model for Lignin Depolymerization. ChemSusChem. 2009. Vol. 2(3), P. 215-217.

10. Van den Bosch S., Schutyser W., Koelewijn S.F., Renders T., Courtin C.M., Sels B.F. Tuning the lignin oil $\mathrm{OH}$-content with $\mathrm{Ru}$ and $\mathrm{Pd}$ catalysts during lignin hydrogenolysis on birch wood. Chemical Communications 2015. Vol. 51(67), P. 13158-13161.

11. Li C., Zheng M., Wang A., Zhang T. One-pot catalytic hydrocracking of raw woody biomass into chemicals over supported carbide catalysts: simultaneous conversion of cellulose, hemicellulose and lignin. Energy \& Environmental Science 2012. Vol. 5(4), P. 6383-6390.

12. Yan N., Zhao C., Dyson P.J., Wang C., Liu L.-t., Kou Y. Selective Degradation of Wood Lignin over Noble-Metal Catalysts in a Two-Step Process. ChemSusChem. 2008. Vol. 1(7), P. 626-629.

13. Parsell T., Yohe S., Degenstein J., Jarrell T., Klein I., Gencer E., Hewetson B., Hurt M., Kim J.I., Choudhari H., Saha B., Meilan R., Mosier N., Ribeiro F., Delgass W.N., Chapple C., Kenttämaa H.I., Agrawal R., Abu-Omar M.M. A synergistic biorefinery based on catalytic conversion of lignin prior to cellulose starting from lignocellulosic biomass. Green Chemistry. 2015. Vol. 17(3), P. 1492-1499.

14. Klein I., Marcum C., Kenttämaa H., Abu-Omar M.M. Mechanistic investigation of the $\mathrm{Zn} /$ Pd/C catalyzed cleavage and hydrodeoxygenation of lignin. Green Chemistry. 2016. Vol. 18(8), P. 23992405 .

15. Song Q., Wang F., Cai J., Wang Y., Zhang J., Yu W., Xu J. Lignin depolymerization (LDP) in alcohol over nickel-based catalysts via a fragmentation-hydrogenolysis process. Energy \& Environmental Science. 2013. Vol. 6(3), P. 994-1007. 
16. Torr K.M., van de Pas D.J., Cazeils E., Suckling I.D. Mild hydrogenolysis of in-situ and isolated Pinus radiata lignins. Bioresource Technology 2011. Vol. 102(16), P. 7608-7611.

17. Zhang K., Li H., Xiao L.-P., Wang B., Sun R.-C., Song G. Sequential utilization of bamboo biomass through reductive catalytic fractionation of lignin. Bioresource Technology 2019. Vol. 285, P. 121335.

18. Li H., Fang Z., Smith R.L., Yang S. Efficient valorization of biomass to biofuels with bifunctional solid catalytic materials. Progress in Energy and Combustion Science 2016. Vol. 55, P. 98-194.

19. Quesada-Medina J., Cremades F., Olivares Carrillo P. Organosolv extraction of lignin from hydrolyzed almond shells and application of the $\delta$-value theory. Bioresource technology 2010. Vol. 101, P. 8252-8260.

20. Лавренов А.В., Басова И.А., Казаков М.О., Финевич В.П., Бельская О.Б., Булучевский Е.А., Дуплякин В.К. Катализаторы на основе анион-модифицированных оксидов металлов для получения экологически чистых компонентов моторных топлив. Рос. хим. журнал 2007. Vol. LI(4), P. 75-84. [Lavrenov A.V., Basova I.A., Kazakov M.O., Phinevich V.P., Belskaya O.B., Buluchevskii E.A., Duplyakin V.K. Catalysts based on anion-modified metal oxides for the production of environmentally friendly components of motor fuels. Rus. Chem. J. 2007. Vol. LI(4), P. 75-84. (In Russ.)]

21. Sluiter J.B., Ruiz R.O., Scarlata C.J., Sluiter A.D., Templeton D.W. Compositional Analysis of Lignocellulosic Feedstocks. 1. Review and Description of Methods. Journal of Agricultural and Food Chemistry 2010. Vol. 58(16), P. 9043-9053.

22. Sjöström E,Alén R. Analytical Methods in Wood Chemistry, Pulping, and Papermaking Berlin-Heidelberg, Springer-Verlag, 1999.

23. Renders T., Van den Bossche G., Vangeel T., Van Aelst K., Sels B. Reductive catalytic fractionation: state of the art of the lignin-first biorefinery. Current Opinion in Biotechnology 2019. Vol. 56, P. 193-201.

24. Rinaldi R., Jastrzebski R., Clough M.T., Ralph J., Kennema M., Bruijnincx P.C.A., Weckhuysen B.M. Paving the Way for Lignin Valorisation: Recent Advances in Bioengineering, Biorefining and Catalysis. Angewandte Chemie International Edition 2016. Vol. 55(29), P. 8164-8215. 